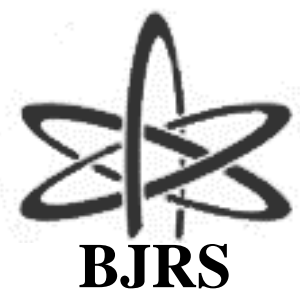

BRAZILIAN JOURNAL

OF

RADIATION SCIENCES

09-02B (2021) 01-17

\title{
Modified methodology for determining the temperature profiles of inverted $u$-tubes steam generators used in pwr power plants
}

\author{
Chaves $^{\mathrm{a}}$ L.C., Zotin ${ }^{\mathrm{b}}$ J.L.Z., Curi ${ }^{\mathrm{b}}$ M.F. \\ ${ }^{a}$ Nuclebrás Equipamentos Pesados S.A - NUCLEP, Department of Industrial Engineering, 23825-410, Itaguaí, Rio de \\ Janeiro, Brazil \\ ${ }^{b}$ Centro Federal de Educação Tecnológica Celso Suckow da Fonseca - CEFET/RJ - UnED Itaguaí, Department of \\ Mechanical Engineering, 23812-101 Itaguaí, Rio de Janeiro, Brazil \\ corresponding author: marcos.curi@cefet-rj.br
}

\begin{abstract}
The most common and reliable methodology for determining temperature profiles of Inverted U-tubes Steam Generators is using Computational Fluid Dynamics (CFD) programs. In this work, we developed a modified methodology using the Wolfram Mathematica software to determine, with good approximation, the temperature profiles of this kind of equipment. The first step was to determine expressions for the water's physical properties in the operational conditions, like density, thermal conductivity, specific heat, and dynamic viscosity. Geometrical parameters like tubes diameter and sub-channel flowing area and the flow parameters like flow mass of primary and secondary fluid were also considered. The numbers of Reynolds, Prandtl, and Nusselt were then determined and, consequently, the variation of convective coefficients and the global heat transfer coefficient. With subroutines that use the method of the lines, we could solve the partial differential equations applied to parallel and countercurrent heat exchangers with no phase change. The U-tubes SG were divided into two regions. The first one was calculated considering a parallel heat exchanger. The second one was calculated considering a countercurrent heat exchanger, depending on the primary and secondary circuit's flow direction. During the phase change, a constant variation of the enthalpy was considered, making the primary fluid temperature decrease following a linear behavior. Using the developed methodology called "Enthalpy Ruler", the
\end{abstract}


encountered results were considered adequate since the defined lengths are compatible with the constant variation of the enthalpy from the compressed liquid to saturated steam. 


\section{INTRODUCTION}

The study of thermal-hydraulics systems in nuclear engineering becomes more relevant in the last years in the actual worldwide scenario where sustainable energy sources are constantly being studied. Many studies on how safe a nuclear system is and how to design a correct power plant for the specific application with accurate mathematical solutions generate many studies in the area [1 - 4].

This paper focuses on the study of the Pressurized Water Reactor (PWR) and its parameters. The primary circuit of a PWR nuclear power plant consists of a reactor, a pressurizer (PZR), reactor coolant pumps (RCP), and steam generators (SG). The water pumped by the RCPs flows through the reactor core, increasing its temperature, and takes the thermal energy from the reactor to the SG. The water transfers its thermal energy to the secondary circuit in the SG, decreasing its temperature, flows to the RCP, and then returns to the reactor [4].

Inside the inverted U-tubes steam generators (SG), the coolant from the reactor (hot leg) flows through the inlet nozzle located on the bottom, flows inside the U-tubes, and goes out through the outlet nozzle also located on the bottom (cold leg). In the next section, we could note that a vertical plate inside the bottom chamber avoids mixing the inlet and the outlet fluids. That is called the "primary side" $[4,5]$.

Outside the U-tubes flows the water of the secondary circuit. The water flows through the feedwater ring, goes down between the external and the internal shell, goes up through the U-tubes becoming steam, due to the heat transferred from the primary circuit, and goes out through the outlet nozzle on the top of the SG to feed the turbines, that is the "secondary side" [6]. The next section shows a schematic design of the previous description for the steam generator. .

In this work, we used the operational parameters from Angra 1 NPP to determine the fluid's thermal physics and thermal-hydraulics behavior under the operating conditions of a PWR. These parameters were also used to develop the equations for making the analyses. The convective coefficients and the overall heat transfer coefficients were not considered constant.

Two equations were developed to describe the variation of the overall heat transfer coefficient for each sub-cooled region on the secondary side of the SG as a function of the secondary fluid temperature and the convective coefficients. The results were considered adequate since the defined lengths 
are compatible with the constant variation of the enthalpy from the compressed liquid to saturated steam.

\section{PROBLEM FORMULATION FOR STEAM GENERATION ANALYSIS}

An example of a 2-loop nuclear power plant is shown in Figure 1. Each loop contains a steam generator and an RCP. Figure 2 shows the secondary flow, represented by the green arrows, and the primary fluid by the red and blue colors. It is important to note that the secondary fluid always flows from the bottom to the top of the steam generator and the primary fluid flows from the bottom to the top at the inlet part and from top to bottom toward the outlet nozzle.

Figure 1: Main equipment of the primary circuit of a 2-loop PWR.

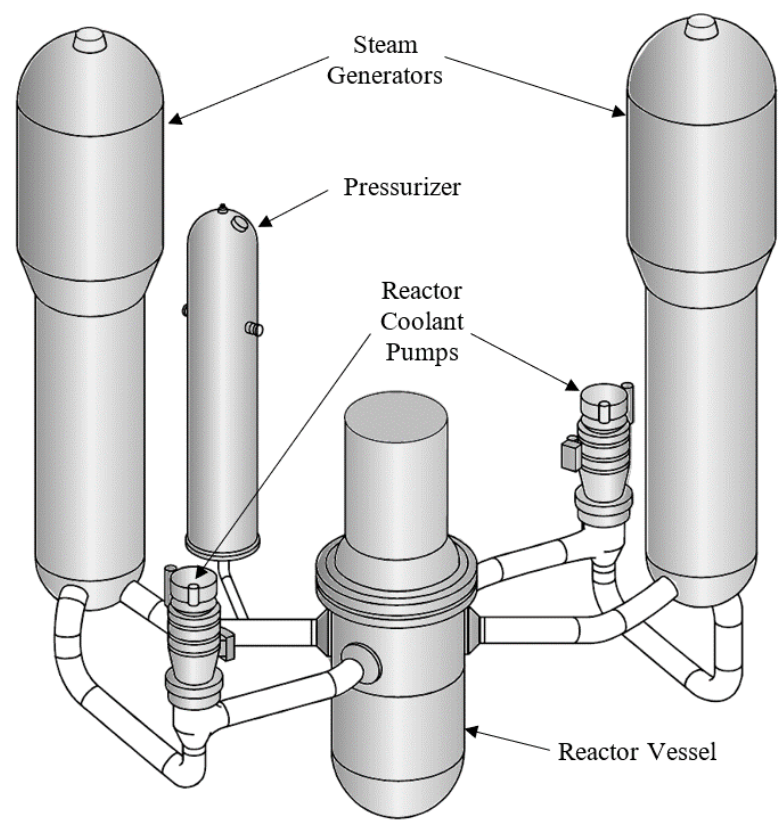

Source: Westinghouse, The Westinghouse Pressurized Water Reactor Nuclear Power Plant, Pittsburgh: Westinghouse Electric Corporation, 2005.

Figure 2: Flow of the primary and the secondary circuit inside the SG. 


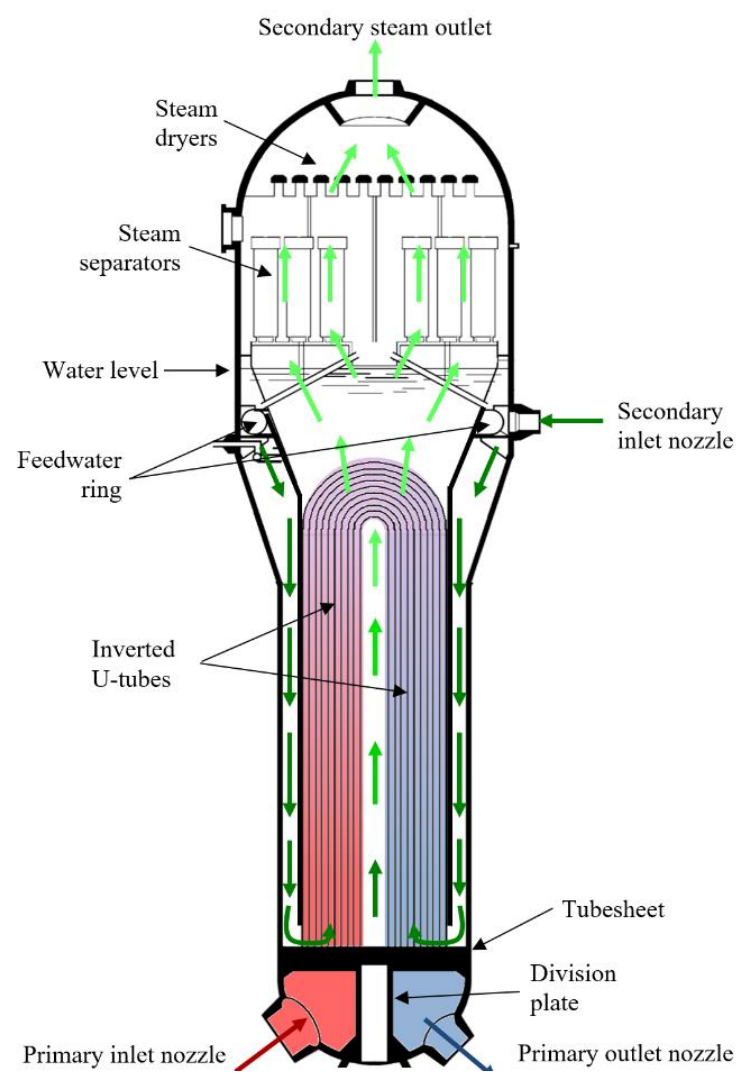

Source: Westinghouse, The Westinghouse Pressurized Water Reactor Nuclear Power Plant, Pittsburgh: Westinghouse Electric Corporation, 2005.

Table 1 contains the main data for the steam generator analysis. According to [7], this type of SG has its tubes following a triangular pitch, as shown in Figure 3.

Figure 3: Triangular pitch, similar to Angra 1.

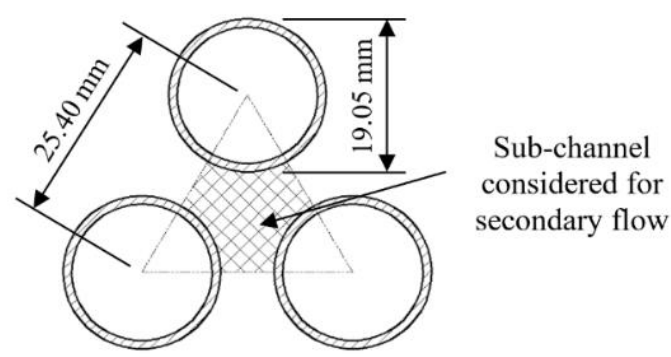

Source: Todreas, N. E. ; Kazimi, M. S. Nuclear Systems: Thermal Hydraulic Fundamentals. $2^{\text {nd }}$ ed. Florida: CRC Press, 2011. INCROPERA, F. P., et al. Fundamentals of Heat and Mass Transfer, $6^{\text {th }}$ ed., Rio de Janeiro: LTC, 2008

Table 1: Operational parameters from Angra 1 SG. [5, 6]. 


\section{Steam Generators operational data}

$\begin{array}{cc}\text { Primary / secondary sides pressure }\left[\mathrm{kgf} / \mathrm{cm}^{2}\right] & 157.1 / 64.7 \\ \text { Mass flow of primary / secondary in each part }[\mathrm{kg} / \mathrm{s}] & 4479 / 257.5 \\ \text { Primary side inlet / outlet temperature }\left[{ }^{\circ} \mathrm{C}\right] & 324.2 / 287.5 \\ \text { Feedwater inlet temperature }\left[{ }^{\circ} \mathrm{C}\right] & 221.1 \\ \text { Steam outlet temperature }\left[{ }^{\circ} \mathrm{C}\right] & 279.2 \\ \text { Tube wall thickness }[\mathrm{mm}] & 1.05 \\ \text { Number of tubes } & 5428 \\ \text { Inconel tubes thermal conductivity }\left[\mathrm{W} / \mathrm{m} .{ }^{\circ} \mathrm{C}\right] & 12.1\end{array}$

Therefore, in order to optimize the analysis of the Steam Generator, the heat transferred from primary to secondary fluid was studied, assuming that the inlet tubes (Part 1) were considered as a parallel current heat exchanger and the outlet tubes (Part 2) were considered as a countercurrent heat exchanger, as shown in Figure 4.

Figure 4: Selection parts to steam generator analysis.

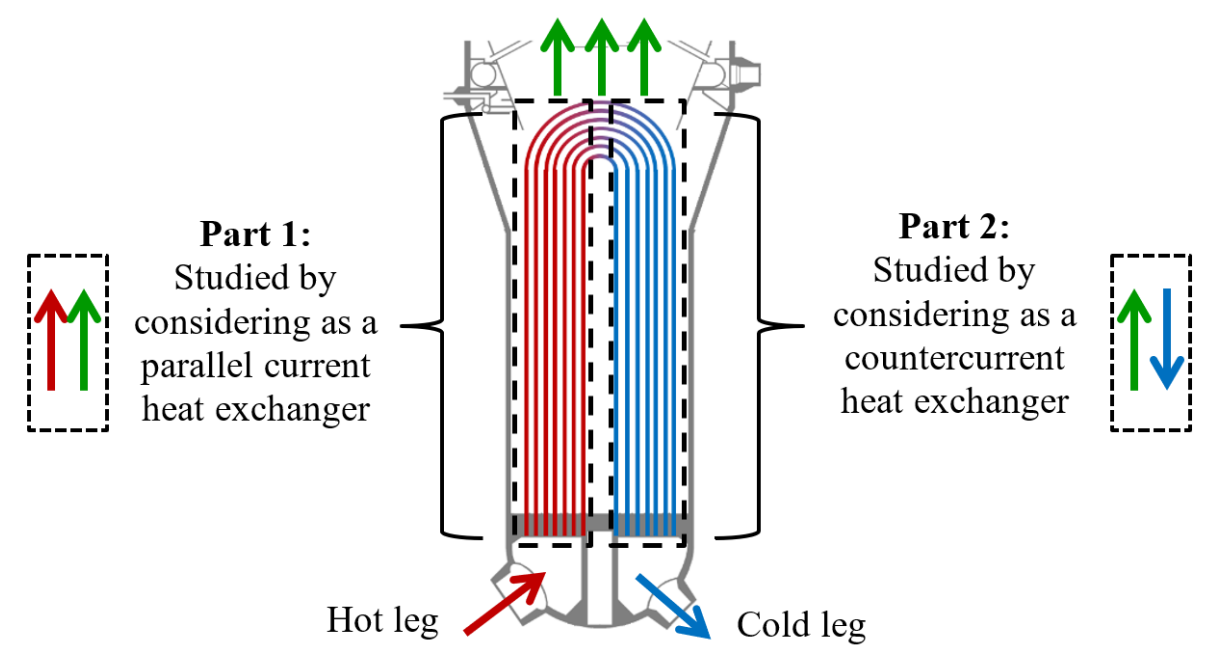

It is important to know that the developed equations must be applied only in the subcooled region of the secondary fluid. In other words, it should be used only where the secondary fluid presents a 
liquid phase. For Part 1, a typical parallel current heat exchanger profile was analyzed to obtain a general equation to model it in Mathematica software, as shown in Figure 5.

Figure 5: Analysis of a typical profile of a parallel current heat exchanger.

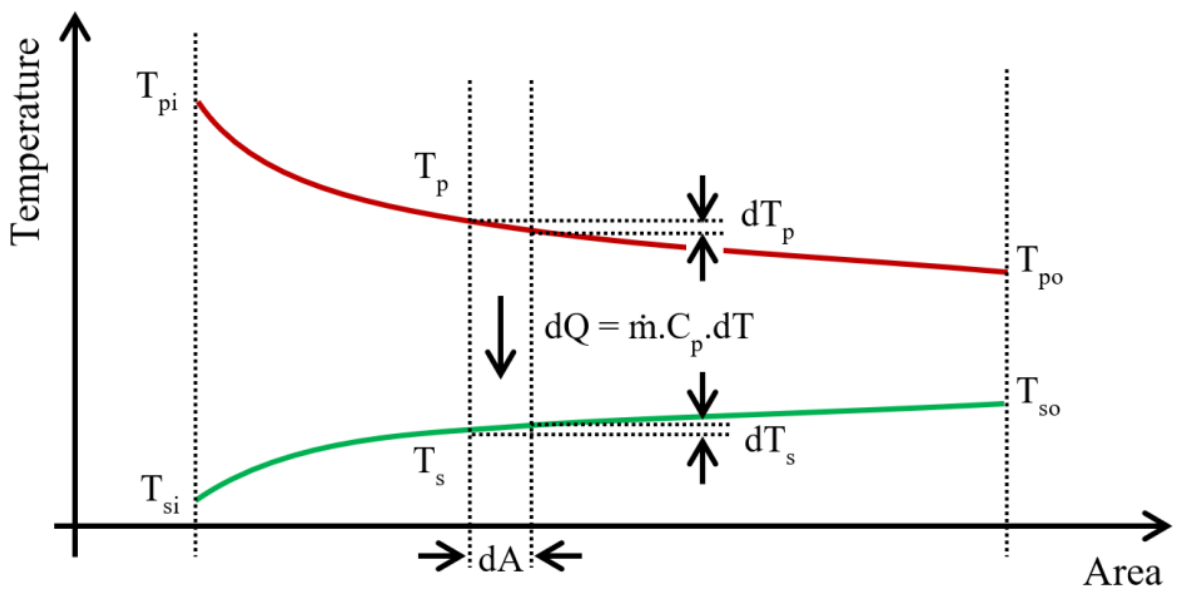

Through the analysis studied in [8], it was possible to develop the general equation of the parallel current heat exchanger, allowing to set the following equation:

$$
\frac{d T_{p}}{d A}+U \cdot \boldsymbol{X}^{\prime} \cdot T_{p}=-\frac{\dot{m}_{p} \cdot c_{p_{p}}}{\dot{m}_{s} \cdot c_{p_{s}}} \frac{d T_{p}}{d A}+U \cdot \boldsymbol{X}^{\prime} \cdot\left(T_{s i}+\frac{\dot{m}_{p} \cdot c_{p_{p}}}{\dot{m}_{s} \cdot c_{p_{s}}} \cdot\left(T_{p i}-T_{p}\right)\right)
$$

Where:

$$
\boldsymbol{X}^{\prime}=\left(\frac{1}{\dot{m}_{p} \cdot c_{p_{p}}}+\frac{1}{\dot{m}_{s} \cdot c_{p_{s}}}\right)
$$


For Part 2, a typical profile of the countercurrent heat exchanger was analyzed to obtain a general equation to model it in Mathematica software, as shown in Figure 6. Using the same methodology, the equation of the countercurrent heat exchanger is given by:

$$
\frac{d T_{p}}{d A}+U \cdot \boldsymbol{X}^{\prime \prime} \cdot T_{p}=\frac{\dot{m}_{p} \cdot c_{p_{p}}}{\dot{m}_{s} \cdot c_{p_{s}}} \frac{d T_{p}}{d A}+U \cdot \boldsymbol{X}^{\prime \prime} \cdot\left(T_{s i}+\frac{\dot{m}_{p} \cdot c_{p_{p}}}{\dot{m}_{s} \cdot c_{p_{s}}} \cdot\left(T_{p}-T_{p o}\right)\right)
$$

Where:

$$
\boldsymbol{X}^{\prime \prime}=\left(\frac{1}{\dot{m}_{p} \cdot c_{p_{p}}}-\frac{1}{\dot{m}_{s} \cdot c_{p_{s}}}\right)
$$

Figure 6: Analysis of a typical profile of a countercurrent heat exchanger.

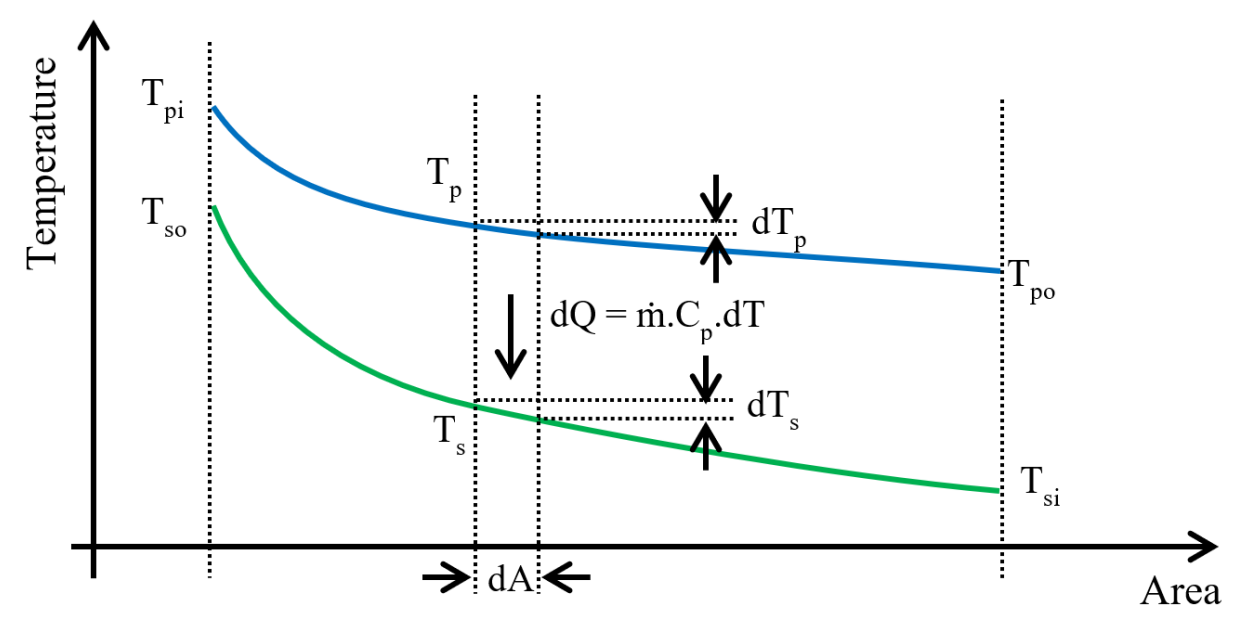

Where $T$ is the coolant temperature $\left[{ }^{\circ} \mathrm{C}\right], A$ is the heat transfer area $\left[\mathrm{m}^{2}\right], \dot{m}$ is the coolant mass flow in a single channel $[\mathrm{kg} / \mathrm{s}], c_{p}$ is the coolant specific heat $\left[\mathrm{kJ} / \mathrm{kg} .{ }^{\circ} \mathrm{C}\right]$ and subscripts $p, s, i$ and $o$ are referring to primary, secondary, inlet and outlet, respectively. 
An important parameter widely used when studying heat exchangers is the overall heat transfer coefficient $(U)$, that depends on the convective coefficient $(h)$, which are determined by the number of Reynolds $(R e)$, Prandtl $(P r)$, Nusselt $(N u)$ and the friction factor $(f)$ of the flow tubes, internally and externally. In this study, $N u$ was obtained by the Gnielinski correlation [9]. Then, the convective coefficient is given by:

$$
h=\frac{k}{D} \cdot \frac{\left(\frac{f}{8}\right) \cdot\left(\left(\frac{\rho \cdot V \cdot D}{\mu}\right)-1000\right) \frac{\mu \cdot c_{p}}{k}}{1+12,7\left(\frac{f}{8}\right)^{0,5}\left(\left(\frac{\mu \cdot c_{p}}{k}\right)^{\frac{2}{3}}-1\right)}
$$

Where $\rho$ is the density $\left[\mathrm{kg} / \mathrm{m}^{3}\right], \mu$ is the dynamic viscosity $\left[\mathrm{N} . \mathrm{s} / \mathrm{m}^{2}\right]$ and $k$ is the thermal conductivity $[\mathrm{W} / \mathrm{m} . \mathrm{K}]$ as a function of the primary and secondary temperature. In this work the friction factor $(f)$ is given by Churchill correlation $[4,9]$, as follows:

$$
f=8\left(\left(\frac{8}{R e}\right)^{12}+\left(A+\left(\frac{37530}{R e}\right)^{16}\right)^{-1.5}\right)^{\frac{1}{12}}
$$

Where:

$$
\boldsymbol{A}=\left(-2.457 \cdot \ln \left(\left(\frac{7}{R e}\right)^{0.9}+0.27 \frac{\varepsilon}{D}\right)\right)^{16}
$$

\subsection{Expressions for the fluid properties}

According to [4], the primary circuit in Angra 1 works with the pressure of $157,1 \mathrm{kgf} / \mathrm{cm}^{2}$, and the secondary circuit works with $64,7 \mathrm{kgf} / \mathrm{cm}^{2}$. Through linear interpolations in thermodynamics 
tables from [10], it was possible to define the equations which describe the fluid properties under each condition, as shown from Figure 7 to Figure 10.

Figure 7: Water density as a function of the temperature and pressure.

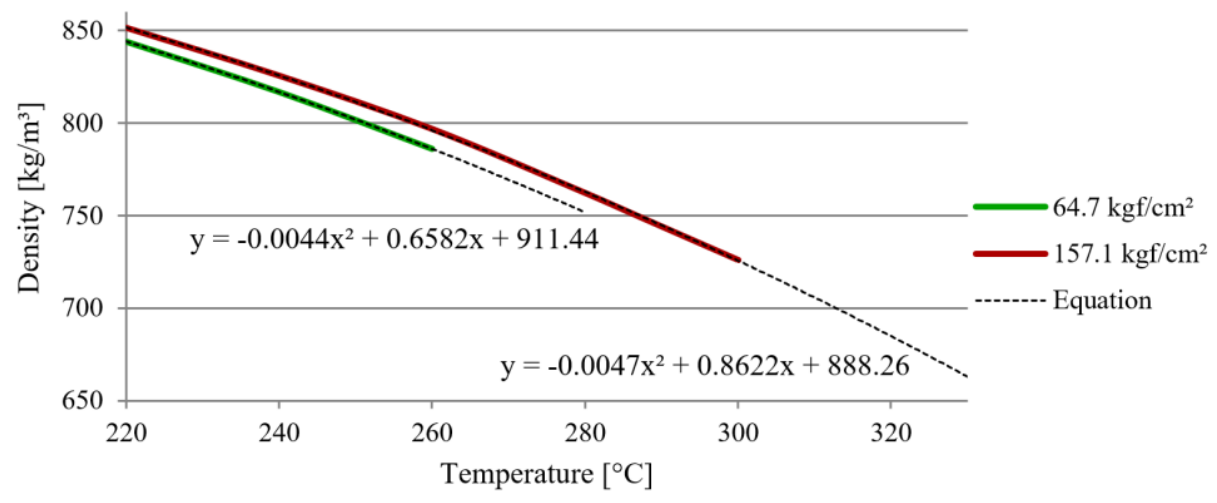

Figure 8: Water dynamic viscosity as a function of the temperature and pressure.

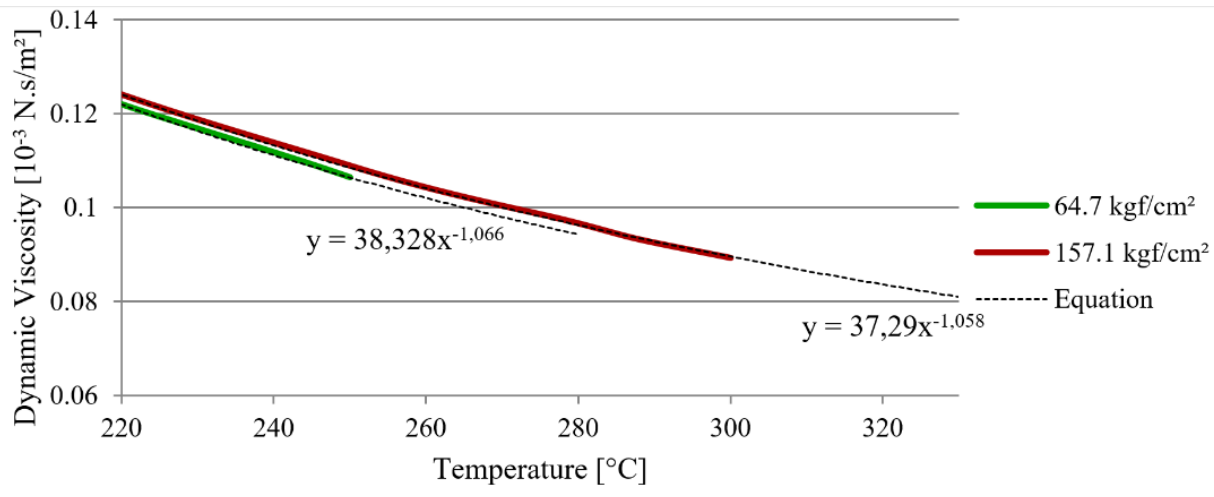

Figure 9: Water specific heat as a function of the temperature and pressure.

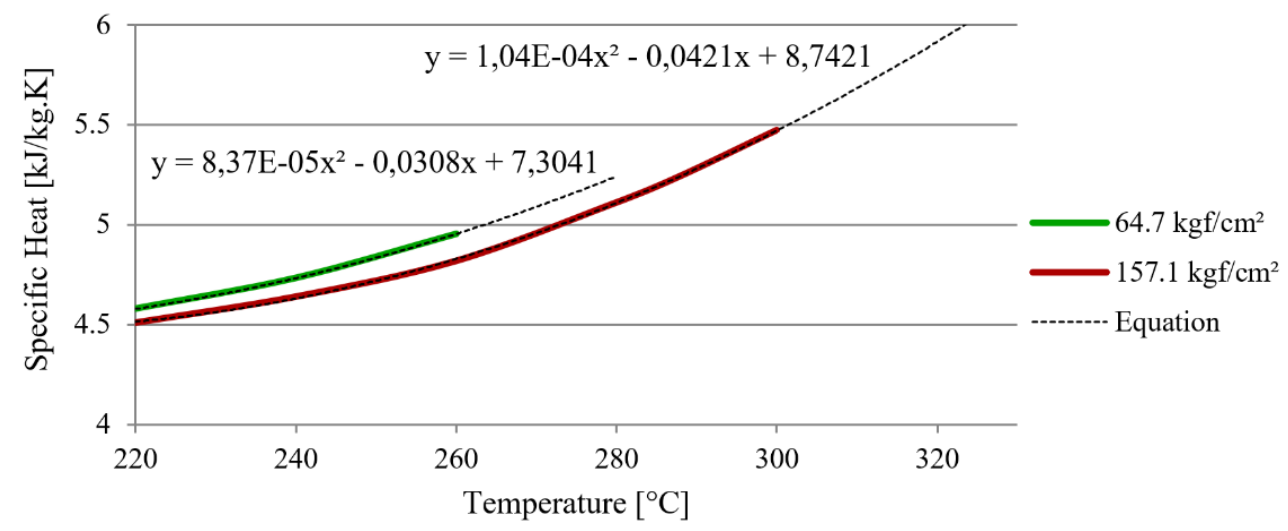


Figure 10: Water thermal conductivity as a function of the temperature and pressure.

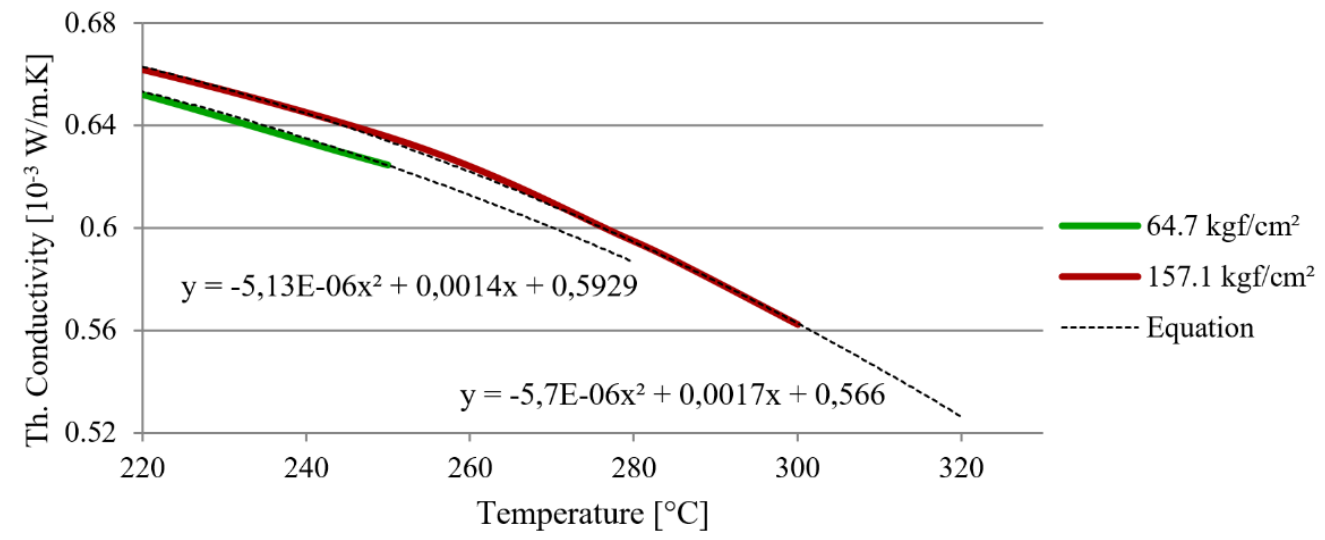

For each property, $T$ is the desired temperature, in ${ }^{\circ} \mathrm{C}$. For density $(\rho)$, under $64.7 \mathrm{kgf} / \mathrm{cm}^{2}$ and $157.1 \mathrm{kgf} / \mathrm{cm}^{2}$, the equations are, respectively:

$$
\begin{aligned}
& \rho_{64}=-0.0044 . T^{2}+0.6582 . T+911.44 \\
& \rho_{157}=-0.0047 . T^{2}+0.8622 . T+888.26
\end{aligned}
$$

For dynamic viscosity $(\mu)$, under $64.7 \mathrm{kgf} / \mathrm{cm}^{2}$ and $157.1 \mathrm{kgf} / \mathrm{cm}^{2}$, respectively:

$$
\begin{aligned}
& \mu_{64}=38.328 . T^{-1.066} \\
& \mu_{157}=37.29 . T^{-1.058}
\end{aligned}
$$

For specific heat $\left(c_{p}\right)$, under $64.7 \mathrm{kgf} / \mathrm{cm}^{2}$ and $157.1 \mathrm{kgf} / \mathrm{cm}^{2}$, respectively:

$$
\begin{aligned}
& c_{p_{64}}=8,37 \cdot 10^{-5} \cdot T^{2}-0,0308 \cdot T+7,3041 \\
& c_{p_{157}}=1,04 \cdot 10^{-4} . T^{2}-0,0421 . T+8,7421
\end{aligned}
$$


Finally, for thermal conductivity $(k)$, under $64.7 \mathrm{kgf} / \mathrm{cm}^{2}$ and $157.1 \mathrm{kgf} / \mathrm{cm}^{2}$, respectively:

$$
\begin{gathered}
k_{64}=-5,13 \cdot 10^{-6} \cdot T^{2}+0,0014 \cdot T+0,5929 \\
k_{157}=-5,7 \cdot 10^{-6} \cdot T^{2}+0,0017 \cdot T+0,566
\end{gathered}
$$

\section{RESULTS AND DISCUSSION}

During the heat transfer from the primary to secondary fluid, it is important to know the behavior of the overall heat transfer coefficient before solving Equation 1 and Equation 3. So, Equation 5 to Equation 15 were used, coupled to Equation 5 and Equation 6, to determine the convective coefficients. According to [11], the average roughness $(\varepsilon)$ of titanium and nickel alloy tubes are defined as $0.05 \mathrm{~mm}$. Figure 11 shows the overall heat transfer coefficient behavior.

Figure 11: Overall heat transfer coefficient as a function of the secondary temperature.

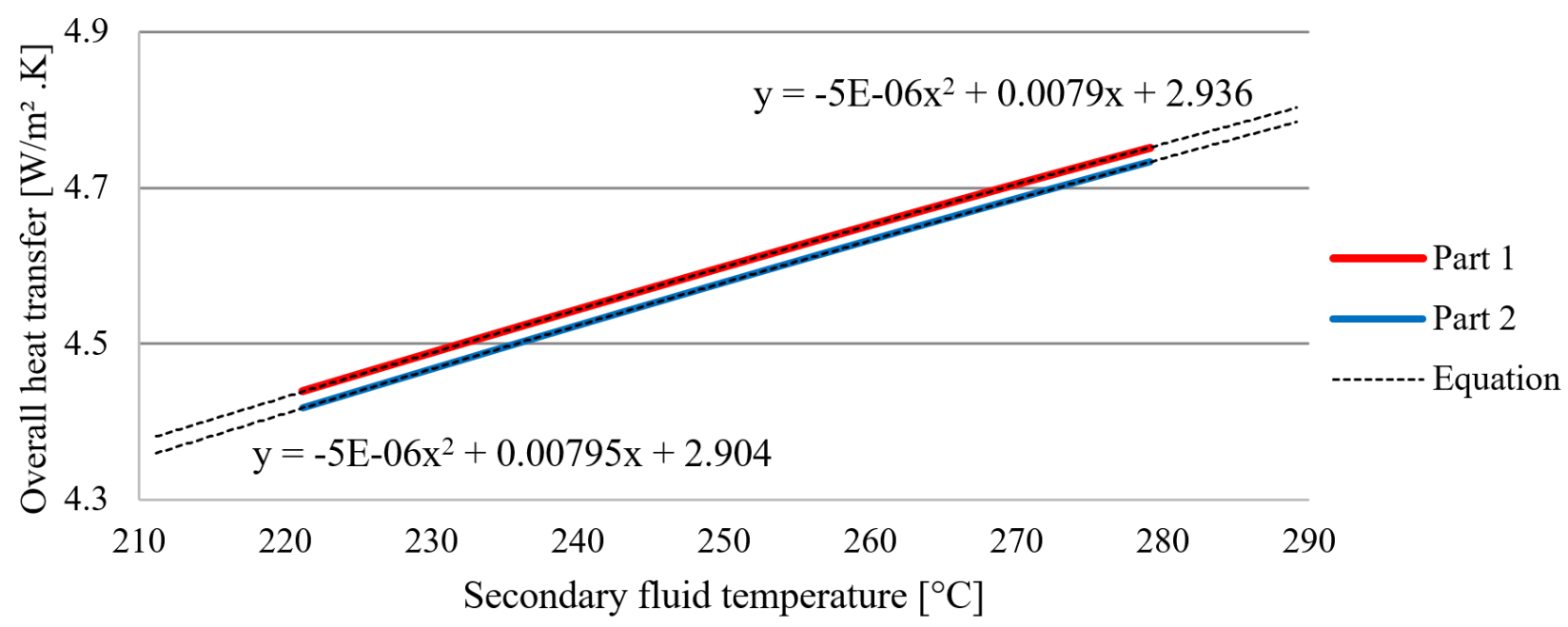

The overall heat transfer coefficient, as a function of the secondary temperature, for the analysis of Part 1 and Part 2, is given by Equation 16 and Equation 17, respectively: 


$$
\begin{gathered}
U_{\text {Part } 1}=-5 \cdot 10^{-6} \cdot T_{s}{ }^{2}+0,0079 . T_{s}+2.936 \\
U_{\text {Part } 2}=-5 \cdot 10^{-6} \cdot T_{s}{ }^{2}+0,00795 . T_{s}+2.904
\end{gathered}
$$

Now we can solve Equation 1 and Equation 3 coupled to the others and define the SG temperatures profiles via Wolfram Mathematica subroutines that use the method of lines for numerical solutions [12]. Looking at Figure 12 and Figure 13, it is possible to note that the secondary's temperature decreases much more than the primary temperature. It happens because of the large difference between the primary and secondary thermal capacity, which depends on the mass flow.

Figure 12: Temperature profile in the subcooled region of Part 1.

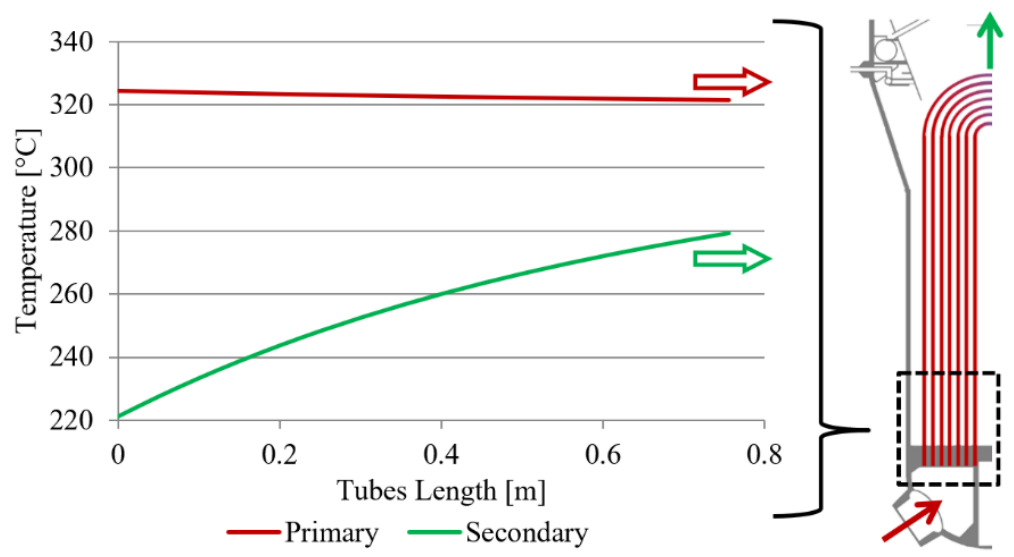

Figure 13: Temperature profile in the subcooled region of Part 2.

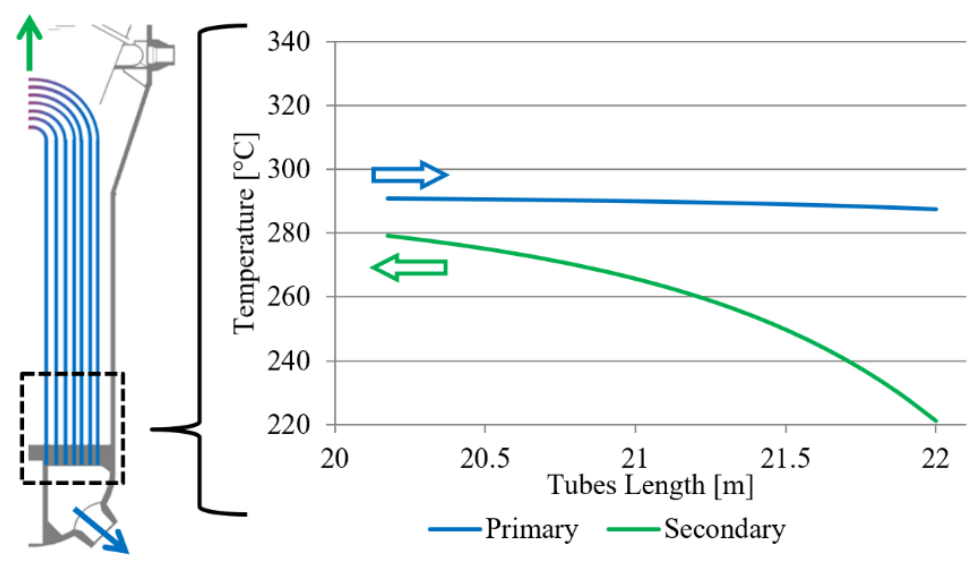


In Part 1, the secondary needs $0.77 \mathrm{~m}$ to reach the saturation temperature, while in Part 2, it needs $1.82 \mathrm{~m}$ to reach the same condition. It happens due to the higher difference in temperature between the primary and secondary in Part 1 . The overall temperature profile of an inverted U-tubes SG is shown in Figure 14.

Figure 14: Overall Steam Generator temperature profile.

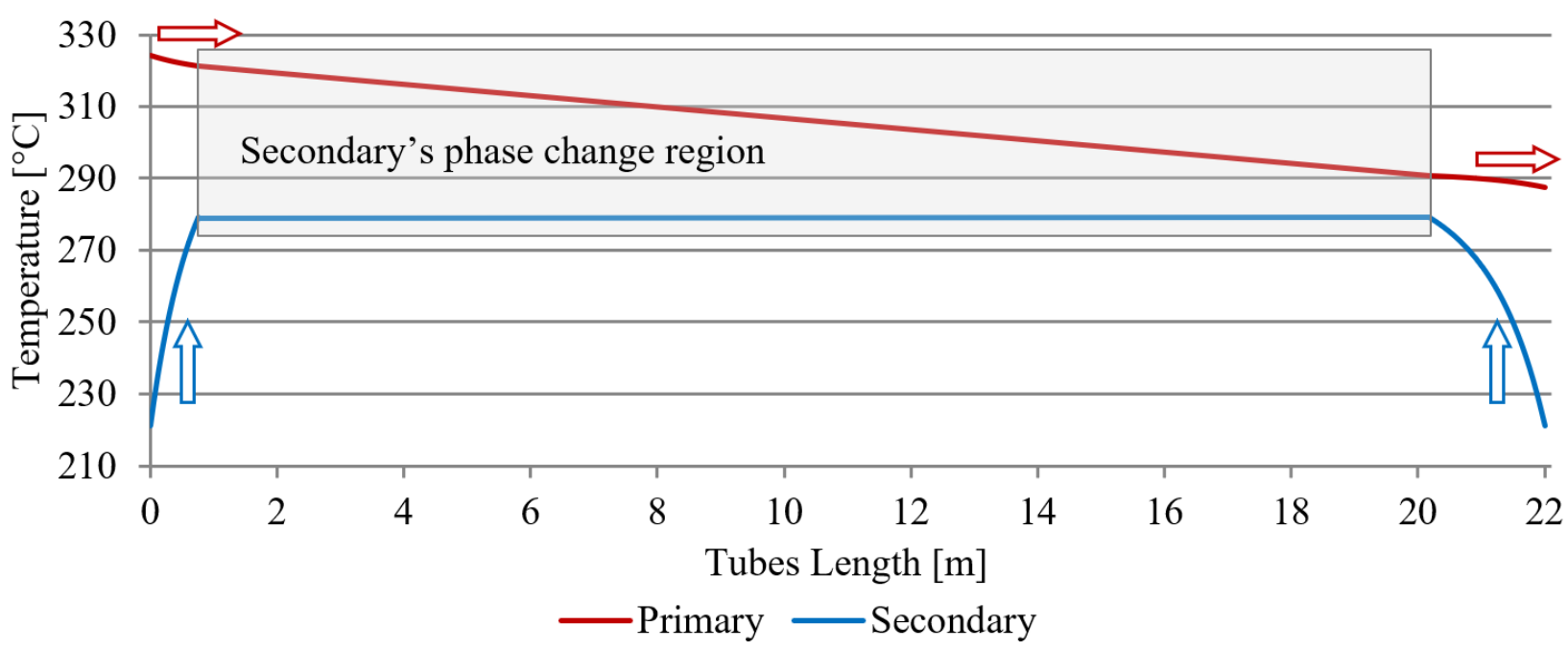

Real profiles were not found in the available literature. Therefore, a methodology called "Enthalpy Ruler" [8] was developed to evaluate the defined lengths necessary for the secondary fluid to reach the saturation point. This methodology is based on a ruler with values of constant variation of the secondary fluid enthalpy and the tubes' average height. A comparison made to evaluate the results is presented in Figure 15.

\section{CONCLUSION}

According to Figures 12 and 13, the average tube length calculated to secondary's fluid reaches the saturation was $1.29 \mathrm{~m}$. Considering that the boiling turns the heat transfer more difficult (due to low heat transfer coefficients of the steam), in a real situation, the length of $1.54 \mathrm{~m}$, encountered with 
the Enthalpy Ruler, tends to decrease approaching to the calculated value. Therefore, only knowing the operation parameters like temperature, pressure and mass flow at inlet and outlet and some geometric information of the tubes is enough to describe the thermal behavior of an inverted U-Tubes steam generator using the presented methodology.

Figure 15: Results evaluation through Enthalpy Ruler method.
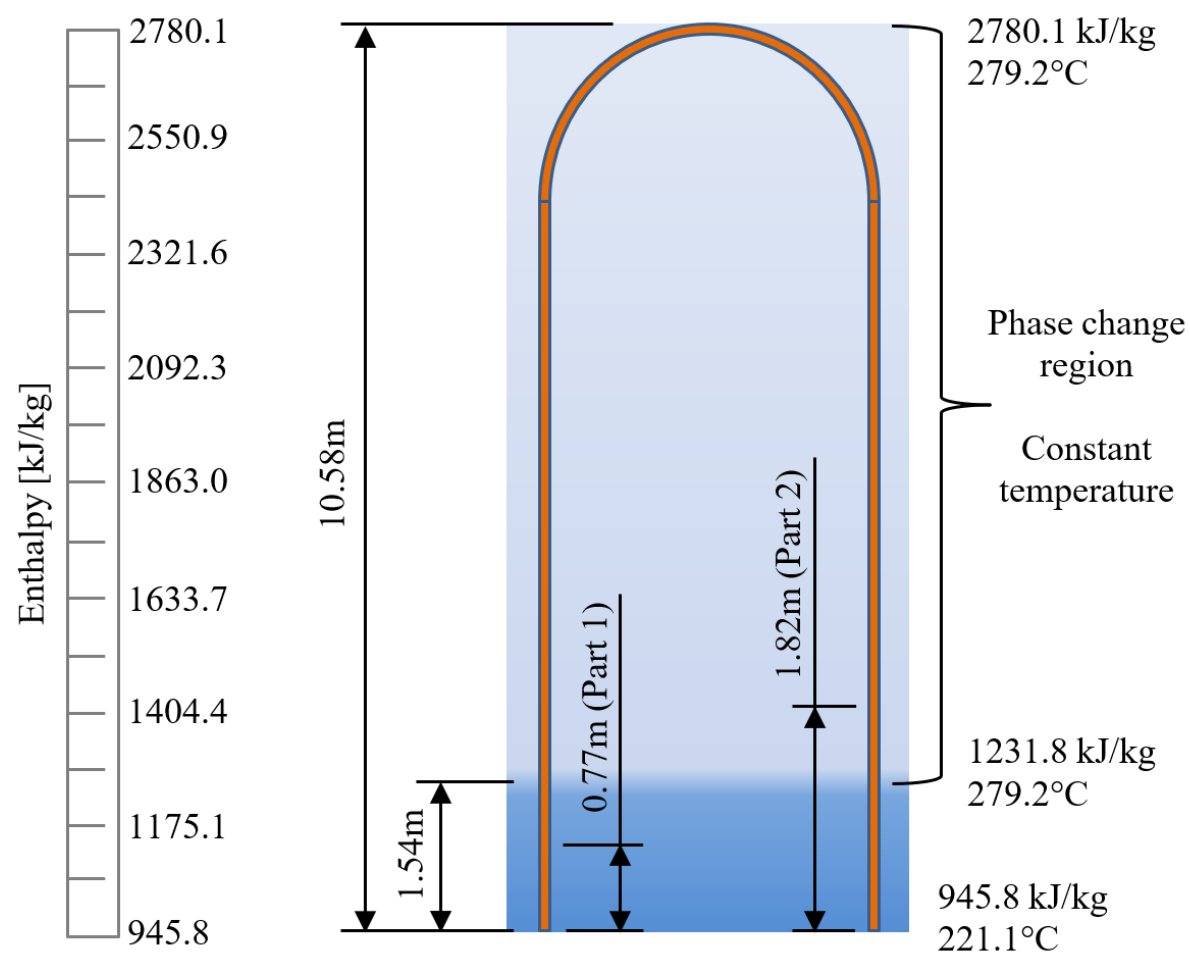

Even though the results were considered adequate, the equation describing the variation of the overall heat transfer coefficient is still under improvements to consider more parameters and make the results more reliable. The developed methodology called "Enthalpy Ruler" proved to be a good way to evaluate if the encountered values provide results that make sense, avoiding large deviations when the results need to be interpreted and when you do not have any real and precision data for making comparisons. 
For future works, instead of considering only an average tube with the vertical flow, it is important to consider the horizontal effects on the beginning of the contact between the secondary fluid and the U-tubes. We are working on this because knowing the thermal-hydraulic parameters of this type of equipment is important to continue developing ever more efficient equipment.

\section{ACKNOWLEDGMENT}

The authors acknowledge the support of Centro Federal de Educação Tecnológica Celso Suckow da Fonseca - CEFET/RJ, Equipamentos Pesados S.A - NUCLEP, Instituto de Engenharia Nuclear IEN and Universidade Federal do Rio de Janeiro -UFRJ.

\section{REFERENCES}

[1] BORGES, D. S. ; LAVA, D. D. ; GUIMARÃES, A. C. F. ; MOREIRA, M. L. Nondeterministic method to analysis of the aging effects in PWR power plants components. Annals of Nuclear Energy, p. 1-10, 2015.

[2] MANTECÓN, J. G.; NETO, M. N. Simplified CFD model of coolant channels typical of a platetype fuel element: an exhaustive verification of the simulations. Brazilian Journal of Radiation Sciences. 07-02B, 2019.

[3] CURI, M. F.; DE SAMPAIO, P. A. B.; GONÇALVES JUNIOR, M. A. Study of natural convection with a stabilized finite element formulation. Computational Thermal Sciences. 9(6), p.513-527, 2017.

[4] TODREAS, N. E. ; KAZIMI, M. S. Nuclear Systems: Thermal Hydraulic Fundamentals. $2^{\text {nd }}$ ed. Florida: CRC Press, 2011. INCROPERA, F. P., et al. Fundamentals of Heat and Mass Transfer, $6^{\text {th }}$ ed., Rio de Janeiro: LTC, 2008.

[5] EletronuClear. Nuclear Power Plant Basic Systems. SBUN 2014. Rio de Janeiro, Eletronuclear, 2014. 
[6] WeStinghouse, The Westinghouse Pressurized Water Reactor Nuclear Power Plant, Pittsburgh: Westinghouse Electric Corporation, 2005.

[7] BUENO, A. G.; GARCIA, JOSE J. J. Almaraz NPP Steam Generator Performance, NDT.net, Bad Breisig, 2012.

[8] CHAVES, L. C., Análise termodinâmica do circuito primário da usina nuclear Angra 1 e implementação dos parâmetros definidos em um submarino de propulsão nuclear, Undergraduate Dissertation, Rio de Janeiro, Centro Federal de Educação Tecnológica Celso Suckow da Fonseca, 2017.

[9] INCROPERA, F. P., et al. Fundamentals of Heat and Mass Transfer, $6^{\text {th }}$ ed., Rio de Janeiro: LTC, 2008. NORSOK. Process design - P-001. Strandveien: Norwegian Oil Industry Association. 2006.

[10] SCHÜNDER, E. U. Heat Exchanger Design Handbook, Washington, New York, London: Hemisphere Publishing Corporation, 1983.

[11] NORSOK. Process design - P-001. Strandveien: Norwegian Oil Industry Association. 2006..

[12] CHAVES, L. C., SOUZA Y. L., FERREIRA L. S. F., CURI M. F. Definition of Thermal Hydraulic profile of a Steam Generator for Naval Nuclear Propulsion via thermodynamic analysis of Angra 1 Steam Generator, In : 17TH BRAZILIAN CONGRESS OF THERMAL SCIENCES AND ENGINEERING, Águas de Lindóia : Associação Brasileira de Engenharia e Ciências Mecânicas, 2018. 